\title{
Increased thirst and hunger in adult rats undernourished as infants: an alternative explanation
}

\author{
By J. L. SMART AND J. DOBBING \\ Department of Child Health, The Medical School, \\ University of Manchester, Oxford Road, \\ Manchester $M_{13} 9 P T$
}

(Received 23 Yune r976-Accepted 9 September 1976)

\begin{abstract}
1. Rats were undernourished in early life by feeding their mothers a restricted quantity of a good-quality diet throughout lactation. Their undernutrition continued postweaning from 25 to $42 \mathrm{~d}$ of age, after which they were fed $a d$ lib. Control rats were well nourished at all times.

2. Behavioural assessment of thirst was carried out on adult males. These were deprived of water for $23 \mathrm{~h} / \mathrm{d}$ throughout the period of testing. Compared to control rats, previouslyundernourished (PU) rats pressed a lever at a higher rate in a Skinner box to gain a water reward, drank more frequently during their first $5 \mathrm{~min}$ in an unfamiliar cage, and tended to run more quickly down an alleyway for water. PU rats also drank more ( $/ \mathrm{kg}$ body-weight $\left.{ }^{0.75}\right)$ of a quinine solution ( $\mathrm{g} / \mathrm{l}$ ) when this was available to them ad lib. as their only source of fluid.

3. A second group of rats was growth-retarded during gestation and the suckling and early postweaning periods. The rats had free access to food from $42 \mathrm{~d}$ of age. In adulthood their ad lib. food and water consumption was measured. PU males ate and drank more (/kg body-weight ${ }^{0.75}$ ) than control males.

4. These results indicate that adult rats which have been undernourished in early life display increased thirst. An attempt is made to explain this finding, together with their previously-demonstrated enhanced hunger drive, purely in terms of gross anatomical and physiological differences.
\end{abstract}

One of the best-documented effects of early undernutrition is hunger drive (reviewed by Bronfenbrenner, 1968). That is, when animals are tested, months after their early experience of nutritional deprivation, they display enhanced responsiveness in 'food-getting' situations. Hence serious reservations have been expressed about the interpretation of results from tests of learning ability in previously-undernourished (PU) animals, which have utilized food as a reward (Barnes, 1967; Baird, Widdowson \& Cowley, I97I ; Smart, Dobbing, Adlard, Lynch \& Sands, 1973). Thirst has sometimes been used as an alternative to hunger in such tests, presumably in the expectation or hope of motivational equality in the various experimental groups, for whom intentionally-imposed thirst had played no part in their early experience (D'Amato, 1960; Simonson \& Chow, 1970). The present study was started, based on this assumption, as an investigation of conditional discrimination in PU rats. However, it soon became clear that the assumption of equivalent thirst was not warranted and the direction of the study was changed to investigate this phenomenon in its own right. 
METHODS

Rats

Expt I

The rats were of the black-and-white hooded Lister strain. All mother rats had previously borne and reared one litter. The control (C) group of young rats were well fed throughout their lives. Their mothers were given a good-quality diet (Mouse Cubes; Oakes Ltd, Congleton, Cheshire) ad lib. at all times and they had free access to the same diet after weaning at $25 \mathrm{~d}$. The diet contained $(/ \mathrm{kg}): 32 \mathrm{~g}$ crude oil, $193 \mathrm{~g}$ crude protein, $40 \mathrm{~g}$ crude fibre and $13.3 \mathrm{MJ}$ metabolizable energy. The PU group of young rats were growth-retarded from birth to $42 \mathrm{~d}$ of age. Their mothers received a restricted quantity of the good-quality diet throughout lactation $(\mathrm{g} / \mathrm{d}): 15$ in week $\mathrm{I}$, 20 in week 2, 25 from the beginning of week 3 to weaning at $25 \mathrm{~d}$. These amounts comprised about half those taken by mothers of $\mathrm{C}$ rats in the corresponding periods. From weaning to $42 \mathrm{~d}$ of age the PU group of young rats was given a small quantity of the same food $\left(3.5 \mathrm{~g} / \mathrm{d}\right.$ from 25 to $34 \mathrm{~d}, 4^{\circ} \circ \mathrm{g} / \mathrm{d}$ from 35 to $\left.42 \mathrm{~d}\right)$, which was enough to allow only slight bodily growth (see Fig. I). From $42 \mathrm{~d}$ of age they were fed ad lib. All rats had free access to water during the period of rearing. Litters were reduced to eight at birth. Only male rats were kept beyond weaning and these were housed two/cage from weaning to the start of behavioural testing, after which they were housed singly.

There were twenty-four $\mathrm{C}$ rats from six source litters and twenty-four PU rats also from six litters. These were tested in two batches each comprising twelve $\mathrm{C}$ and twelve PU animals. The batches which were subjected to each of the tests, and their ages at testing are given in Table $\mathrm{I}$.

\section{Tests of behaviour}

The animal rooms were on a $12 \mathrm{~h}$ white-light $-\mathrm{I} 2 \mathrm{~h}$ red-light cycle switching from white to red at 10.00 hours. Rats were tested during their red-light phase in a room adjacent to the animal room. White-light illumination was necessary for two of the tests (Table $\mathrm{r}$ ).

The rats were kept on a $23 \mathrm{~h}$ water-deprivation/d schedule during the $4^{-6}$ weeks of behavioural testing, except on the last test when a quinine solution ( $\mathrm{g} / \mathrm{l})$ was available $a d l i b$. Water was available to the rats during the test of behaviour and in their 'home' cage for a short time after the test. The length of the latter period was such that water was available for a total of $I \mathrm{~h} / \mathrm{d}$.

Conditional discrimination. Full details will not be given of this test, since testing was discontinued after 2 weeks when it became clear that there were motivational differences between the $\mathrm{C}$ and $\mathrm{PU}$ groups. During week $\mathrm{x}$ individual rats were allowed to wander freely about a ' $T$ '-shaped maze for 10 min on each of $5 \mathrm{~d}$. Water was available at the ends of both of the 'arms' of the maze at this stage. The procedures adopted in week 2 were intended to train the rats to run from the start point at the base of the maze into one of the two 'arms' for a water reward. Rats were placed at the start point, allowed to run to the end of an 'arm', to remain there for a few 
Table I. Expt I. Type of illumination for each behavioural test and age at start of testing of two batches of control and previously-undernourished rats*

\begin{tabular}{|c|c|c|c|}
\hline \multirow[b]{2}{*}{ Test $\uparrow$} & \multirow[b]{2}{*}{$\begin{array}{l}\text { Illumination } \\
\text { during testf }\end{array}$} & \multicolumn{2}{|c|}{$\begin{array}{c}\text { Age at start of testing } \\
\text { (weeks) }\end{array}$} \\
\hline & & Batch I & Batch 2 \\
\hline Conditional discrimination & White & I 3 & $\S$ \\
\hline Alley test & Red & $\S$ & 17 \\
\hline Novel cage test & Red & 15 & 20 \\
\hline Operant conditioning & White & I6 & $\S$ \\
\hline Quinine test & Cyclic $\|$ & 19 & $2 I$ \\
\hline
\end{tabular}

* For details of feeding regimens, see p. 422.

+ For details, see p. 422-424.

I With the exception of the quinine test, rats were tested during the red-light phase of their light cycle.

$\S$ Rats were not subjected to that test.

II $12 \mathrm{~h}$ white-light-1 $2 \mathrm{~h}$ red-light.

seconds and were then lifted out and replaced at the start. They were allowed to drink at the end of the 'arm', if they had chosen the correct one. Up to five such runs/d were given. Eleven of the twelve PU rats completed twenty runs in $5 \mathrm{~d}$, whereas only four of the twelve $\mathrm{C}$ rats did so. Several $\mathrm{C}$ animals would neither run nor drink in the maze.

Alley test. An aluminium alleyway was used, I. $6 \times 0.10 \times 0.125 \mathrm{~m}$ high, with a hinged Perspex ceiling. At one end there was a 'start' box, $0.25 \mathrm{~m}$ long, closed by a sliding Perspex door and at the other end the nozzle of a water-bottle projected into the alley.

Training proceeded in two stages: $5 \mathrm{~d}$ of habituation to the alley, $2 \mathrm{~d}$ after which began $5 \mathrm{~d}$ of training to run down the alley. The daily routine during habituation was to place each rat in the 'start' box, release it after $15 \mathrm{~s}$ and allow it to move freely about the alley for a further $10 \mathrm{~min}$. The 'start' routine was the same during training, but, after reaching the water source, the rat was allowed to drink for only $20 \mathrm{~s}$ before being replaced in the 'start' box and the whole procedure repeated. During the training period rats were given three such runs on day $\mathrm{I}$, four runs on day 2 and five runs on each of days 3,4 and 5. 'Times taken to leave the 'start' box (latency) and from leaving the 'start' box to starting to drink at the other end of the alley (running time) were recorded.

Novel cage test. Each rat was taken from its 'home' cage and placed in a clean cage of the same type with a fresh layer of the usual cage litter, wood-shavings, on the floor. The cages were of opaque plastic, $0.41 \times 0.25 \times 0.12 \mathrm{~m}$ high, with a flat wire lid, one end of which was recessed to serve as a food basket. This was full of food pellets. Water was available from a bottle whose ball-tip nozzle projected into the cage. The movement of the ball within the nozzle was distinctly audible when the rat drank and proved to be a most reliable cue to the onset of drinking. A drink was defined as a rapid series of audible licks punctuated by breaks of no more than I s; breaks of more than is differentiated one drink from the next. The frequency and duration of all drinks during a $15 \mathrm{~min}$ test period was recorded. 
Operant conditioning. The operant conditioning procedure was similar to that described by Smart et al. (1973), with the major exception that the rats were rewarded with water rather than food. Briefly, rats were trained to press a lever in a Skinner box to gain a water reward over a minimum of seven daily 25 min sessions. After they had obtained a criterion of at least seventy-five presses/session for a schedule on which they were rewarded every fifth press, they were transferred to a 'variableinterval' schedule. This had a refractory period of variable length during which no reward could be obtained, such that the animals had the opportunity to gain a water reward, on average, every $2 \mathrm{~min}$. This schedule is said to be a sensitive index of level of motivation (Ferster \& Skinner, 1957). The rats were run on this schedule for $3 \mathrm{~d}$. Water rewards of about $0.2 \mathrm{ml}$ were dispensed by a cam-operated dipper feeder.

Quinine test. Rats were given a solution of quinine hydrochloride ( $\mathrm{g} / \mathrm{l})$ as their only source of fluid during a $48 \mathrm{~h}$ period. This bitter solution is not normally acceptable to rats (Munn, 1950). Amounts of fluid removed were noted after 6, 24 and $48 \mathrm{~h}$. The fluid was available to the rats in their 'home' cages from familiar 'water-bottles' with ball-tip nozzles. The amount of fluid lost through dripping and evaporation was measured in a control experiment in which bottles were positioned in uninhabited cages. Thus correction factors were calculated for each bottle and deducted from the total weights of fluid removed after 6,24 and $48 \mathrm{~h}$.

\section{Food and water consumption}

\section{Expt 2}

Food and water consumption, when both were offered ad lib., was measured in another batch of rats with a somewhat different nutritional history. They were growth-retarded during gestation as well as in the suckling and postweaning periods. Their mothers were given $10 \mathrm{~g} / \mathrm{d}$ throughout pregnancy, and then were fed exactly as the underfed mothers described in Expt $\mathrm{I}$; thus their mothers received about half the $a d l i b$. intake for the whole period. They continued to be undernourished postweaning until $42 \mathrm{~d}$ of age as described in Expt I, after which they were fed ad lib. Fourteen $\mathrm{C}$ rats from seven litters and eleven PU rats from six litters were housed singly at 18 weeks of age and their ad lib. food and water consumption measured over a $5 \mathrm{~d}$ period. The mean ( \pm range) temperature and relative humidity of the animal room were $22 \cdot 5 \pm 0.5^{\circ}$ and $55 \pm 7 \%$ respectively.

\section{Statistical analysis}

The significance of differences between mean values was assessed by Student's $t$ test, except where stated otherwise. Instances in which distributions were not Gaussian were analysed by the non-parametric Mann-Whitney U test. All probabilities are two-tailed.

\section{Body-weight}

RESULTS

Expt I

PU rats weighed $67 \%$ less than well-fed $\mathrm{C}$ rats at weaning $(P<0.00 \mathrm{r})$ and $80 \%$ less than $\mathrm{C}$ rats at 6 weeks $(P<0 \cdot 001)$. They did not show 'catch-up' during the 


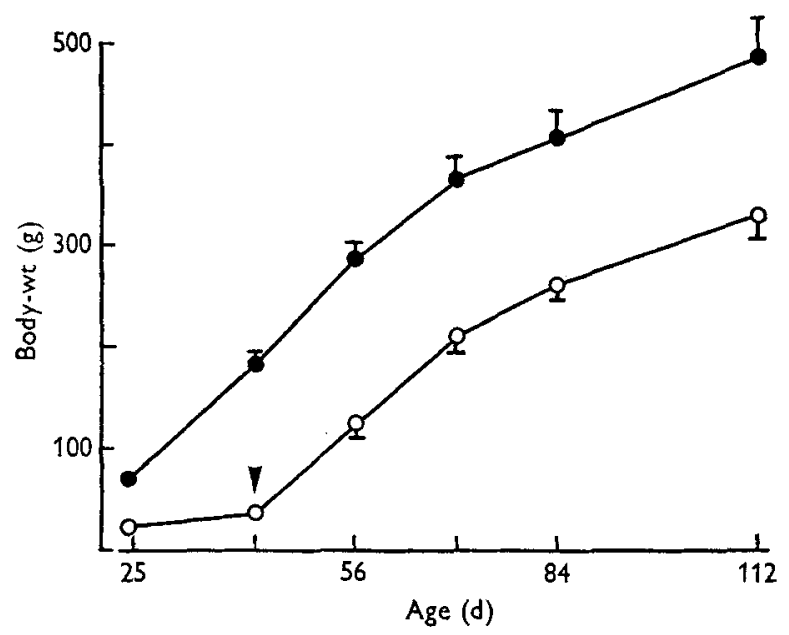

Fig. I. Expt I. Mean ( \pm SD) body-weights of control $(O)$ and previously-undernourished (O) rats from weaning at $25 \mathrm{~d}$ of age. Previously-undernourished rats were underfed from birth to $42(\nabla) \mathrm{d}$ of age, after which they were fed $a d$ lib.; for details, see p. 422.

Table 2. Expt 1. Alley test*: running time(s)† of control $(C)$ and previously-undernourished $(P U)$ rats $\downarrow$ in an alley

(Mean values with their standard errors)

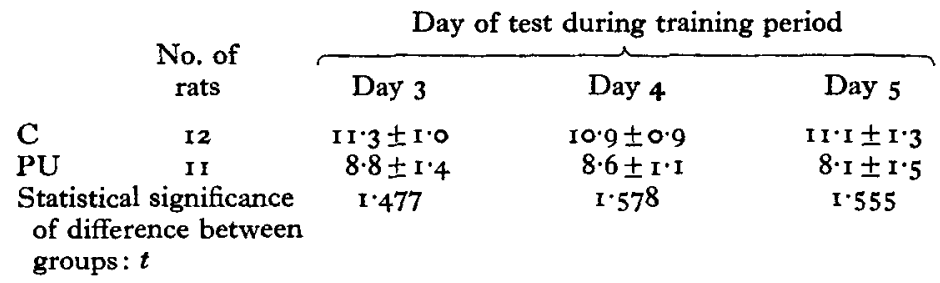

* For details, see p. 423 .

+ Time from leaving 'start' box to starting to drink at the other end of the alley.

$\ddagger$ For details of feeding regimen, see p. 422 .

subsequent nutritional rehabilitation, in that their absolute weight deficit was virtually the same at $\mathrm{I} 6$ weeks as it had been at 6 weeks (Fig. I). Their relative weight deficit was $32 \%$ at 16 weeks $(P<0.001)$.

\section{Behaviour}

Alley test. Latency to leave the 'start' box did not differ between groups. PU rats had somewhat shorter running times than $\mathrm{C}$ rats, but the difference was not statistically significant (Table 2).

Novel cage test. PU rats appeared to be more eager to drink than controls during the first 5 min of the test. Their latency to start drinking was less than half that of $\mathrm{C}$ rats, they drank more often and tended to spend more time drinking (Table 3 ). During the last $10 \mathrm{~min}$ of the $15 \mathrm{~min}$ test drinking was sporadic and relatively infrequent in both groups of animals. 
Table 3. Expt I. Novel cage test*: drinking behaviour of control $(C)$ and previously-undernourished $(P U)$ rats $\dagger$

(Mean values with their standard errors)

\begin{tabular}{|c|c|c|c|c|c|}
\hline \multirow{3}{*}{ No. of rats } & \multicolumn{2}{|c|}{ C } & \multicolumn{2}{|c|}{ PU } & \multirow{3}{*}{$\begin{array}{c}\text { Statistical } \\
\text { significance } \\
\text { of difference } \\
\text { between } \\
\text { groups: } P=\ddagger\end{array}$} \\
\hline & \multicolumn{2}{|c|}{22} & \multicolumn{2}{|c|}{22} & \\
\hline & Mean & $\mathbf{S E}$ & Mean & SE & \\
\hline Latency§ to drink (s) & $87 \cdot 9$ & I7`7 & $42 \cdot 9$ & $6 \cdot 8$ & 0.069 \\
\hline No. of drinks in Ist $5 \mathrm{~min} \|$ & 10.2 & $1 \cdot 3$ & $14 \cdot 3$ & $\mathrm{I} \cdot \mathbf{2}$ & 0.020 \\
\hline Time spent drinking in & $45^{\circ} 9$ & $5 \cdot 9$ & $6 I \cdot 6$ & 57 & 0.066 \\
\hline
\end{tabular}

* For details, see p. 423 .

$\dagger$ For details of feeding regimen, see p. 422 .

$\ddagger$ Mann-Whitney U test.

$\S$ Time taken to leave the 'start' box.

II A drink was defined as a rapid series of audible licks punctuated by breaks of no more than $\mathrm{r} s$; breaks of more than is differentiated one drink from the next.

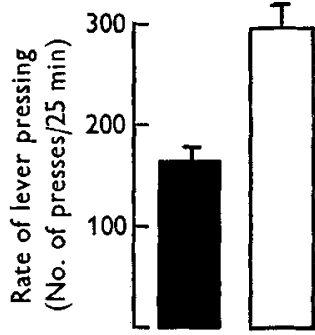

Day $1^{*}$

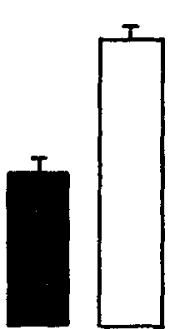

Day 2

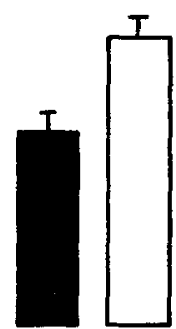

Day 3

Fig. 2. Expt I. Mean ( $\pm \mathrm{sE}$ ) rate of lever pressing (no. of presses $/ 25 \mathrm{~min}$ ) of control (a) and previously-undernourished $(\square)$ rats for a water reward in a Skinner box. They were run on a 'variable interval' ( $2 \mathrm{~min}$ ) schedule; for details, see p. 424. Previously-undernourished rats were underfed from birth to $42 \mathrm{~d}$ of age, after which they were fed ad lib.; for details, see p. 422 .

Operant conditioning. On all $3 \mathrm{~d}$ of the 'variable-interval' schedule the PU rats pressed the lever at a higher rate than $\mathrm{C}$ rats $(P<0.002$ for days I and $2, P<0.02$ for day 3; Mann-Whitney U test) (Fig. 2).

Quinine test. PU rats drank significantly more quinine solution relative to their body-weight, expressed on a per kg body-weight ${ }^{0.75}$ basis; the reasons for expressing the result in this way are discussed later. There were no significant differences between groups in absolute amounts of quinine solution taken (Table 4).

\section{Food and water consumption}

Expt 2

In absolute terms, C rats ate and drank more than PU rats; yet when intake was expressed on a per kg body-weight $t^{0.75}$ basis the direction of the difference was reversed such that the relative consumption of the $\mathrm{PU}$ rats was significantly the greater (Table 5). The dry weight of the food was $890 \mathrm{~g} / \mathrm{kg}$ wet weight. 
Table 4. Expt I. Quinine test*: weight of a solution of quinine hydrochloride ( $\mathrm{g} / \mathrm{l}$ ) taken by control $(C)$ and previously-undernourished $(P U)$ rats $\dagger$ in 6,24 and $48 h$

(Mean values with their standard errors)

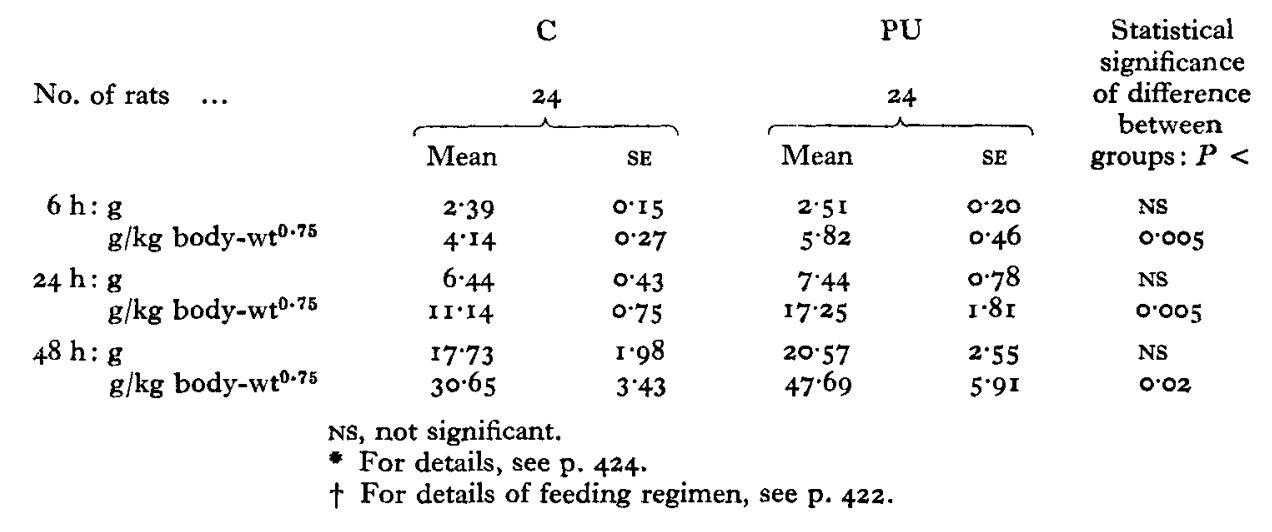

Table 5. Expt 2. Ad lib. food and water intake of control $(C)$ and previously-undernourished $(P U)$ rats*

(Mean values and standard deviations)

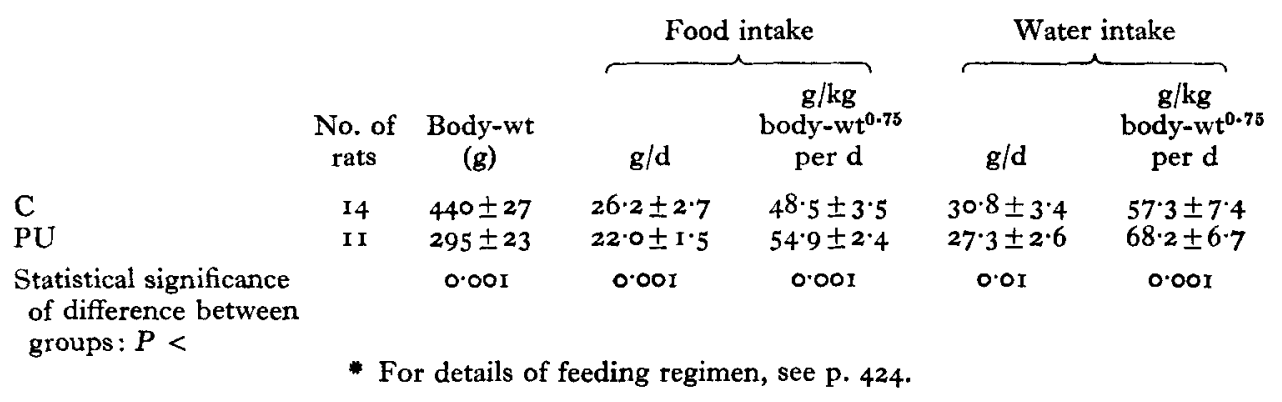

\section{DISCUSSION}

The results indicate strongly that in behavioural terms the PU rats were more thirsty than the $\mathrm{C}$ rats after $23 \mathrm{~h}$ water deprivation. Furthermore, under conditions of ad lib. fluid intake PU rats drank more relative to body-weight than $\mathrm{C}$ rats, and this difference persisted when correction was made for the inequality in size of PU and C animals (intake/kg body-weight ${ }^{0.75}$ ). It may be possible to account for these differences in terms of differences in gross anatomy and physiology, and without recourse to the 'mysteries' of the central nervous system.

Adult $\mathrm{PU}$ rats weigh substantially less than $\mathrm{C}$ animals of the same age; $32 \%$ less in the present experiment. Hence they will have a higher value for surface area: body-weight and consequently their basal energy metabolism $(/ \mathrm{kg})$ will be greater (Brody, 1945). For maintenance they will require more food and water for their size than the larger C rats. Brody (1945) has proposed that for mature mammals basal 
metabolism shows no systematic change with changing body-weight, when expressed on a per $\mathrm{kg}$ body-weight $\mathrm{t}^{0.75}$ basis; that is, that basal metabolism on a per kg bodyweight ${ }^{0.75}$ basis is virtually a constant value. Expressing fluid intake on a per $\mathrm{kg}$ body-weight $t^{0.75}$ basis might therefore be expected to obviate any apparent differences between $\mathrm{PU}$ and $\mathrm{C}$ animals; however, it does not (Tables 4 and 5).

One possible reason why the prediction fails when applied to $\mathrm{PU}$ and $\mathrm{C}$ rats may be that pointed out by Barnes, Kwong, Morrissey, Vilhjalmsdottir \& Levitsky, 1973). Additional to their marked deficit in body-weight, PU rats differ from C rats in body composition. Rats growth-retarded during the suckling period have consistently been shown to be leaner than $\mathrm{C}$ rats (Widdowson \& McCance, r960; Smart, Adlard \& Dobbing, 1974). Likewise male rats suckled by malnourished mothers and given a low-protein diet until $49 \mathrm{~d}$ of age have in adulthood a body fat content of $19^{2} \mathrm{~g} / \mathrm{kg}$ compared with $227 \mathrm{~g} / \mathrm{kg}$ in $\mathrm{C}$ rats (Barnes et al. 1973 ). Such differences in composition, resulting in a higher proportion of metabolically-active tissue in one group than the other, would be expected to lead to differences in over-all metabolic rate. In fact, previously-malnourished rats have a higher oxygen consumption (per kg body-weight ${ }^{0.75}$ ) than $\mathrm{C}$ rats both under conditions of fasting and of ad lib. feeding (Barnes et al. 1973). Associated with such a difference PU rats might need more water on a per $\mathrm{kg}$ body-weight $\mathrm{t}^{.75}$ basis.

It is also possible that the heightened thirst in PU rats may have been a secondary consequence of increased hunger drive. Allowing that the usual dry, pelleted food was always available while ad lib. fluid intake was being measured and before behavioural testing was carried out, the PU rats may have drunk or sought to drink more because of their greater intake of dry food $\left(\mathrm{g} / \mathrm{kg}\right.$ body-weight $\left.{ }^{0.75}\right)$.

Thus the differences in both body-weight and composition might, directly or indirectly, predispose the PU animals to be more urgently in need of water after a fixed period of deprivation. Hence the behavioural symptoms of this urgency recorded in this study are perhaps not particularly surprising on the basis of this argument. The same, of course, holds true for many of the reports of heightened hunger drive in animals which have had an early history of nutritional deprivation (for review, Bronfenbrenner, I 968 ; also, Barnes, Neely, Kwong, Labadan \& Frañková, 1968; Smart et al. 1973; Lynch, Smart \& Dobbing, 1975). Instances of abnormal hunger drive in rats after undernutrition during the suckling period will have occurred in association with permanent stunting of bodily growth and may well be explicable on the basis of differences in body size and composition.

Thirst is almost always imposed in behavioural investigations by depriving animals of water for a fixed period of time, very often $23 \mathrm{~h} / \mathrm{d}$ as in the present experiments. However, methods of generating a controlled amount of hunger are more varied, and it may be worth examining them for the possibility of differential effects on $\mathrm{C}$ and PU animals. There are three basic methods: (I) 'fixed-interval' deprivation, (2) maintenance at a proportion of 'free-feeding' weight, (3) feeding a fixed ration daily. 'Fixed-interval' deprivation of water was used in the present experiments and the previous discussion of this method applies equally to food. One problem with the 'fixed-interval' deprivation method is that animals repeatedly subjected to 
this regimen show progressive change in level of motivation, as measured behaviourally (Davenport \& Goulet, 1964). Maintaining animals at a fixed proportion, e.g. $80 \%$, of their pre-deprivation weight goes some way towards overcoming this difficulty. This is particularly effective if allowance is made for growth by feeding sufficient to allow growth along a curve representing $80 \%$ of the predicted 'free-feeding' weight (Davenport \& Goulet, I964). However, there is every likelihood of a differential effect of this regimen on C and PU animals. PU rats, having smaller fat reserves, would be expected to be more severely affected. The effects of feeding a fixed ration daily are less easy to predict. If the ration for both groups were, for example, $50 \%$ of the $\mathrm{C}$ animals' daily ad lib. intake, then the PU animals might even be less affected than the $\mathrm{C}$ rats because their daily food intake, in absolute terms, is less than that of the $\mathrm{C}$ rats. Theoretically the best method would appear to be feeding each individual animal the same proportion of its own average ad lib. intake.

An alternative and arguably more reliable method of equating levels of motivation is to titrate food deprivation $v$. some simple behavioural index of hunger drive before proceeding to more complex behavioural analysis. Thus, for example, the amount of the daily food ration could be adjusted according to lever-pressing rate in a Skinner box in order to achieve consistently a predetermined rate.

The widespread demonstration of lasting motivational effects of undernutrition in infancy seriously questions the value of most past attempts to investigate learning in PU animals. They show evidence of exaggerated responsiveness to electric shock (Levitsky \& Barnes, 1970; Smart et al. 1973; Smart, Whatson \& Dobbing, 1975), enhanced hunger drive (see previous discussion) and now increased thirst. Future comparisons of learning in $\mathrm{C}$ and $\mathrm{PU}$ animals must somehow control for these factors, either by equating motivation, measured behaviourally, before testing, or by testing under a range of motivational levels.

The authors thank the Medical Research Council for supporting this research, the National Fund for Research into Crippling Diseases for additional financial assistance and Dr T.S. Whatson for his constructive criticism of drafts of the manuscript.

\section{REFERENCES}

Baird, A., Widdowson, E. M. \& Cowley, J. J. (1971). Br. F. Nutr. 25, 39r.

Barnes, R. H. (1967). Fedn Proc. Fedn Am. Socs Exp. Biol. 26, 144.

Barnes, R. H., Kwong, E., Morrissey, L., Vilhjalmsdottir, L. \& Levitsky, D. A. (1973). F. Nutr. I03, 273 .

Barnes, R. H., Neely, C. S., Kwong, E., Labadan, B. A. \& Fraňková, S. (1968). f. Nutr. 96, 467.

Brody, S. (1945). Bioenergetics and Growth. New York: Hafner.

Bronfenbrenner, U. (1968). In Early Experience and Behavior, p. 629 [G. Newton and S. Levine editors]. Springfield, Illinois: Thomas.

D'Amato, M. R. (1 960). Psychol. Rep. 7, 91.

Davenport, D. G. \& Goulet, L. R. (1964). F. comp. physiol. Psychol. 57, 237.

Ferster, C. B. \& Skinner, B. F. (1957). Schedules of Reinforcement. New York: Appleton-CenturyCrofts.

Levitsky, D. A. \& Barnes, R. H. (1970). Nature, Lond. 225, 468 .

Lynch, A., Smart, J. L. \& Dobbing, J. (1975). Brain Res. 83, 249.

Munn, N. L. (1950). Handbook of Psychological Research on the Rat. Boston, Massachusetts: Houghton Mifflin. 
Simonson, M. \& Chow, B. F. (1970). Y. Nutr. roo, 685.

Smart, J. L., Adlard, B. P. F. \& Dobbing, J. (1974). Biol. Neonate 25, 135 .

Smart, J. L., Dobbing, J., Adlard, B. P. F., Lynch, A. \& Sands, J. (1973). F. Nutr. 103, 1327.

Smart, J. L., Whatson, T. S. \& Dobbing, J. (1975). Br. $\mathscr{~}$. Nutr. 34, 5 I I.

Widdowson, E. M. \& McCance, R. A. (1960). Proc. R. Soc. B 152, 188. 